Check for updates

Montreal

Cite this as: BMJ 2021;375:n2598

http://dx.doi.org/10.1136/bmj.n2598

Published: 25 October 2021

\title{
Covid-19: Moscow re-enters lockdown as cases surge in Russia
}

\section{Owen Dyer}

Moscow is imposing Russia's first major lockdown in over a year as the country seeks to short circuit an autumn surge that has seen cases and deaths climb relentlessly for six weeks.

Moscow's mayor will close businesses, schools, kindergartens, and all shops except groceries and pharmacies for 11 days from 28 October. Bars and restaurants will allow takeout only. Museums and galleries may operate at half capacity, admitting only people with digital vaccine certificates. Unvaccinated people aged over 60 will not be permitted to leave home.

Moscow's coronavirus situation is "developing according to the worst case scenario," the city's mayor, Sergei Sobyanin, wrote in a blog.

Throughout Russia workers will receive a week off starting on 30 October, President Vladimir Putin announced. The measure comes as new cases continue to soar, and Russia's official daily death toll-a figure widely believed to be a serious underestimate-has exceeded 1000 on each of the past six days.

With under a third of Russians fully vaccinated, the Kremlin has begun to voice new exasperation at the prevalence of vaccine scepticism in the country. Mortality is high because of the "unacceptably low level of vaccination," said a Kremlin spokesman last week. "All facilities have been provided to citizens to save their lives by getting inoculated," said Dmitry Peskov, who was himself admitted to hospital with covid in May.

\section{Persuading people}

Putin this week said that he could not understand why some friends of his had not been vaccinated. "I ask, 'Have you been vaccinated?' 'No.' 'Why?' 'Oh, I don't know, I'll wait.' It's strange,” he said. "People with a good education, with academic degrees. I just don't get what's going on."

Critics argue that the Kremlin is a victim of its own success in playing down the pandemic's impact on Russia, leading many citizens to believe that they have no need of vaccination. Russian media have praised Russian vaccines but also sometimes focused on negative or misleading stories about western vaccines, which may have bred a broader vaccine scepticism. Putin himself was vaccinated only in March, and he chose not to admit cameras.

At a foreign policy forum on 21 October Putin again urged Russians to get vaccinated. "There are just two options for everyone-to get sick or to receive a vaccine," he said. "There is no way to walk between the raindrops."

But he rejected vaccine mandates. "I believe we mustn't force it but persuade people and prove to them that vaccination is better than illness," he said. "We must try to increase people's trust in the government's actions. We need to be more convincing and prove it by example."

\section{Miscounting the cost}

But the mistrust begins with the government's figures on cases and deaths, which show numerous statistical anomalies at the local level and an inexplicably lighter toll than in nearby countries such as Poland and Romania, which are more thoroughly vaccinated.

From the pandemic's outset, deaths from covid in Moscow reported by the government agency Rospotrebnadzor were far outstripped by the excess deaths counted in the city's morgue based reporting system. Official deaths from covid are registered by panels that often attribute the cause of death to some other health condition, even with a positive coronavirus test. But Rospotrebnadzor's covid death figures are dwarfed by a spike in all cause excess deaths since the pandemic arrived, in figures compiled by Russia's official statistics agency, Rosstat. ${ }^{1}$

Alexei Raksha, a demographer who quit Rosstat last year after criticising official covid statistics, this month used the agency's data to calculate that Russia had lost 997000 people in the 12 months from October 2020 to September 2021. ${ }^{2}$ The Moscow Times, also working with data obtained from Rosstat, found this month that excess deaths during the pandemic in Russia numbered $660000 .{ }^{3}$ Russia's official death toll stands at 228453 .

1 Dyer O. Covid-19: Russia's statistics agency reports much higher death toll than country's health ministry. BMJ 2021;372:1440 doi: 10.1136/bmj.n440 pmid: 33579671

2 Raksha A. Population estimates. 9 Oct 2021. https://www.facebook.com/rickky.spirewanderer/posts/4457670520967557

3 Russia's coronavirus excess death toll hits 660K. Moscow Times 2021 Oct 8. https://www.themoscowtimes.com/2021/10/08/russias-coronavirusexcess-death-toll-hits-660k-a75254

This article is made freely available for use in accordance with BMJ's website terms and conditions for the duration of the covid-19 pandemic or until otherwise determined by BMJ. You may use, download and print the article for any lawful, non-commercial purpose (including text and data mining) provided that all copyright notices and trade marks are retained. 